\title{
Report
}

\section{Pedestrian Behavior and Service Quality Assessment: A Study at Selected Areas in Rajshahi City Corporation}

\author{
Md. Shakil Ar Salan”, Md. Nahidul Islam, Shazzu Rahman, Hafiza Nazneen Labonno, \\ Nazia Hossain, Hossain Mohiuddin
}

Department of Urban \& Regional Planning, Rajshahi University of Engineering \& Technology, Rajshahi, Bangladesh

Email address:

shakil.ruet@hotmail.com (Md. S. Ar Salan)

*Corresponding author

\section{To cite this article:}

Md. Shakil Ar Salan, Md. Nahidul Islam, Shazzu Rahman, Hafiza Nazneen Labonno, Nazia Hossain, Hossain Mohiuddin. Pedestrian Behavior and Service Quality Assessment: A Study at Selected Areas in Rajshahi City Corporation. International Journal of Transportation Engineering and Technology. Vol. 4, No. 1, 2018, pp. 1-10. doi: 10.11648/j.jitet.20180401.11

Received: August 16, 2017; Accepted: December 19, 2017; Published: January 8, 2018

\begin{abstract}
Walking is the most useable transport mood through all over the world as well as Rajshahi. Maximum people use this mood to go a short distance and sometimes to cover the long distances. For the increasing number of population, it is very urgent to assess and provide proper facilities while they walk. In this research, several methods have been followed to assess pedestrian behavior and the service quality that is provided to facilitate pedestrian. For these three different study areas have been chosen according to commercial, mixed use and residential area. About 98 samples have been taken on the basis of the purposive sampling technique. Both qualitative and quantitative data are considered for this purpose. Quantitative data includes determination of effective walkway width, calculation of average pedestrian space and volume by capacity ratio. Questionnaire survey method has been followed to collect qualitative data. In this case, variables are considered according to the good pedestrian facilities by following literature review. After that, ratio method is used to give relative rankings and weights to the qualitative and quantitative variables. Collected data are analyzed separately for assessing the pedestrian level of service and pedestrian behavior using Microsoft excel. This research revealed that the highest pedestrian flow was in the commercial area. Maximum respondents have been given emphasizes on rehabilitation of illegal establishment, construct the footpath infrastructures and restriction on footpath parking in the commercial and mixed used areas. Recommendations for improving the existing situation have been discussed on the basis of pedestrian given priority.
\end{abstract}

Keyword: Pedestrian, Pedestrian Behavior, Pedestrian Level of Service

\section{Introduction}

Realization of space identification, belongs to an environment and realization of city campus qualities, is the accessible by walking in the environment. Social contacts in the city campus create a social life and it will be reinforced, and caused a cultural cycle and process [1]. Walking is the most efficient and effective mode of transportation for short trips. Although there has been a decline in the popularity of walking, it remains a very commonly employed model of travel. People of almost all ages, both sexes and in all walks of life, walk, set against a background of steadily increasing vehicle numbers and traffic levels. It offers an economical, healthy, environmental friendly movement pattern for the city dwellers. On the basis of population, Rajshahi is fourth largest metropolitan cities of Bangladesh. It is mainly an educational city and the number of heavy vehicle is lower, pedestrian movements is vital for economic development of city life. Population of Rajshahi is increasing day by day with a growth rate of $1.25 \%$. The City constitutes a high urbanization rate of $32.93 \%$ [2]. Increasing population may put pressure on the pedestrian network. As a result pedestrian's demand is increased. At present $41.37 \%$ road of this city is pucca [2]. But unfortunately, most of these roads do not have any efficient and pedestrian friendly sidewalk. A limited number of sidewalks are provided in only commercial areas. There is no 
sufficient sidewalk access in residential or industrial areas of Rajshahi city. Proper attention has been given to study on pedestrian behavior and pedestrian flow characteristics for Rajshahi city to determine the Pedestrian Level of Service (PLOS). This paper mainly shows the PLOS and pedestrian behavioral pattern with the recommendations to build up a better, safe and environment friendly pedestrian walkway network in Rajshahi city.

\section{Literature Review}

Pedestrianism has become an integral part of sustainable modern urban design. Thus, the design, arrangement and development of support infrastructures should be in favor of pedestrian movements to popularize walking. The purpose of this chapter is to explore existing pedestrian literature in order to assess pedestrian behavior, to asses the existing service quality of pedestrian, to identify best practices in pedestrian data collection, analysis, and finaly provide some recommendations for safe, sound and environment friendly environment for the pedestrian. The analysis of pedestrian behaviour ensures that pedestrian facilities are balanced with vehicular facilities and other land uses. To achieve so, pedestrian facilities should be planned and based on the concrete information on user characteristics, travelling patterns and objectives of pedestrian are flow. The facilities also need to be harmonized with the ambient factors that affect the safe, convenience and secure movement of pedestrians. The smooth movement of pedestrians is affected by a number of factors including gradient or roughness of surface [3], riser height of stairways [4]. Rosenbloom, Nemrodov and Barkan [6] applied roadside observations to investigate the differences in pedestrians' behavior by observing two entirely different urban places in terms of religion. Results showed that young and male pedestrians have a tendency to commit violations. Another study [5] also supports the above results which conclude that older pedestrians appreciate sidewalks and crossing facilities much more than younger pedestrians. Holland and Hill [7] consider age and gender differences in road crossing decisions within a theory of planned behavior analysis including intention, situation and risk perception effects on pedestrian.. Moreover, in divided roads, pedestrians behave differently from one side to the median, then from median to the other side of the road [8]. There are few studies on pedestrian behavior in Dhaka City. Rahman, Afrin and Alum [9] tries to measures the level of service (LOS) of walkways in Dhaka city. The study explores the qualitative level of comfort of the pedestrian in Dhaka city by offering six broad categories of roadside walking environment in terms of "1) safety, 2) security, 3) convenience and comfort, 4) continuity of walkways, 5) system coherence and 6) attractiveness" facilities. To assess the quality of pedestrian network and facilities, Landis [10] identified sidewalk capacity, quality of the walking environment, and individual perceptions of comfort/safety as the three main factors that influence 'walkability'. This literature shows that lots of studies have been done to model pedestrian behavior in different sections of roadway in different cities of the world. Unfortunately, no such study was conducted in Rajshahi City which elaborated the behavior and preferences of pedestrian while using the road. This study will focus to fulfil these knowledge gaps. Limitation facing while conduction the survey and some recommendation for creating pedestrian friendly environment based on pedestrian perception are discussed in the last portion of this research paper.

\section{Objectives and Methodology of the Study}

A number of research works are available regarding pedestrian behavior and service quality assessment but in case of Rajshahi City Corporation (RCC), no research has yet been conducted focusing pedestrian behavior and service quality at a time. The objectives of this paper are to assess the behavioral pattern of the pedestrian at selected areas, to assess the service quality of the pedestrian using selected qualitative and quantitative variables and to provide some recommendations for safe, sound and environment friendly environment of pedestrian. Three representative wards $(6,13$ and 26) are considered as the study of Rajshahi City Corporation which indicates the overall land use pattern such as residential, commercial and mixed use. The total population of the study area is about 34,843 . The total sample needed to conduct the study is about 98 with confidence level $95 \%$ and confidence interval 10 which is calculated by using sample calculator. The sample size for the wards 6,13 and 26 are 40,43 and 15 respectively. The broad aim of this study is to assess the pedestrian behavior and service quality of the pedestrian. In this study, purposive sampling technique is used or else it may not fulfill the purpose. On the basis of objective, 11 parameters are considered to determine the pedestrian service quality, which are: effective walkway width, pedestrian flow rate and average pedestrian space, volume by capacity ratio, attractiveness, comfort, convenience, safety, security, system coherence, and system continuity. The parameters are both qualitative and quantitative. Every parameter is given equal weight $\&$ the total weight is 100 . The standard of the highway capacity manual has been used to rate the quantitative parameters. The overall assessment of the pedestrians has been ranked using performance measures (PMs) method. Then obtained information were put in Microsoft excel to analyze them into graphs and charts.

\section{Study Area Profile}

Rajshahi city corporation area is mainly under Boalia Thana. It has 30 wards with households of about 93545 and population is 449756 . Our study areas are Padma Residential as residential area, Laxmipur area as mixed-use area and New Market area as commercial area, in 13,14 and 26 number words respectively.

New market area is one of the busiest areas in Rajshahi City. It is bounded on the east by Rajshahi rail station, on west by Bindur 
Mor, on the south by Rajshahi polytechnic institute and on the north by Rajshahi new market. The walkway facility in this area is not satisfactory. Total length of walkway which is considered as study area is $1897 \mathrm{~m}$. Average width of the walkway is $2.4 \mathrm{~m}$. But most of the walkway area is consumed by street hawker or local street food shop. We will mainly consider the road in front of new market to observe the pedestrian behavior.

Padma residential area is known as Gulshan of Rajshahi city. Padma residential area is at Vodra area just after RUET and before railway station. It is mainly a residential area but a little bit commercial and educational activities also held there. It is in 26 number ward. The population of the ward is 11702 and area is 1078.3 acres. Road width is $10 \mathrm{ft}$. Heavy vehicles are restricted in the area. As no footpath is available, people here use all the roads for walking. Small vehicles run through the area for mainly residential purpose. Also a bypass road is situated near the area.
So traffic flow is also generated for this reason.

Laxmipur area is the center of all medical facilities. Another biggest medical college Rajshahi medical college is located in Laxmipur area. A large number of private clinics (Islami Bank hospital, Mukti clinic, Popular diagnostic center, Raj pathology etc.) also locates this place. Different type of shops specially pharmacy, food corner, medical equipment shops are situated here. The other types of land use are hotel, restaurant, schools (Govt. Laboratory school, Monipuri girls high school), colleges (New govt. degree college), coaching centers, some commercial institution and residential area. So a large number of pedestrian trips are generated in this place but the facility of walkway is not enough to serve the people of this area. In Laxmipur area most of the walk way is consumed by shops or street hawker. Walkway length of Laxmipur area is $2123 \mathrm{~m}$. Average width of the walkway is $2.4 \mathrm{~m}$.

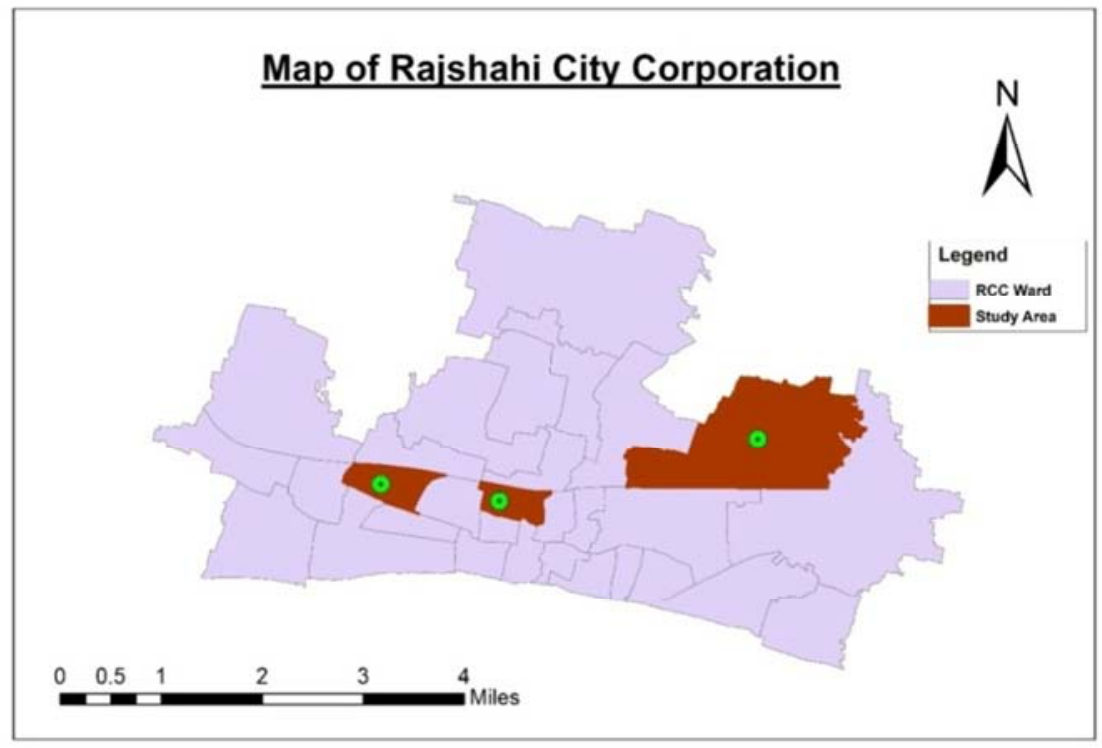

Source: Map Prepared by Researcher, 2017.

Figure 1. Rajshahi city Corporation Map.

\section{Methods for Pedestrian Service Quality Assessment}

1). Highway Capacity Manual (HCM)

HCM [11] defines (Table 1) six level of service from A to F for pedestrian facility, with LOS A being the best and LOS F being the worst where volume capacity ratio $(\mathrm{v} / \mathrm{c})$ is one of the most used index to assess traffic status in cities, in which $\mathrm{v}$ is the total number of pedestrians passing a point in one hour and c for the maximum number of pedestrians that can pass a certain point at the reasonable traffic condition.

Table 1. Pedestrian Level of service Category.

\begin{tabular}{|c|c|c|c|c|c|}
\hline LOS & Average space (sq. m/p) & Flow rate $(\mathrm{p} / \mathrm{sec} / \mathrm{m})$ & Average speed (m/sec) & v/c ratio & Comments \\
\hline A & $>15.7$ & $<0.061$ & $>1.6$ & $<0.45$ & $\begin{array}{l}\text { Free flow, freedom of speed, comfort and } \\
\text { convenience }\end{array}$ \\
\hline B & $12.3-15.7$ & $0.061-0.073$ & $1.35-1.6$ & $0.45-0.60$ & $\begin{array}{l}\text { Stable flow, reasonable freedom of speed and } \\
\text { movement }\end{array}$ \\
\hline $\mathrm{C}$ & $8.5-12.3$ & $0.073-0.084$ & $1.15-1.35$ & $0.60-0.75$ & Need to adjust path to avoid conflicts and also less \\
\hline $\mathrm{D}$ & $7.24-8.5$ & $0.084-0.097$ & $0.9-1.15$ & $0.75-0.9$ & $\begin{array}{l}\text { Speed and ability to pass slower pedestrian } \\
\text { restricted }\end{array}$ \\
\hline $\mathrm{E}$ & $6.2-8.4$ & $0.097-0.121$ & $0.75-0.9$ & $0.9-1$ & $\begin{array}{l}\text { Volume close to the capacity with very limited } \\
\text { ability to pass slower pedestrian }\end{array}$ \\
\hline $\mathrm{F}$ & $<6.2$ & $>0.121$ & $<0.75$ & $>1$ & $\begin{array}{l}\text { Volume exceeds capacity with frequent contact } \\
\text { with other users }\end{array}$ \\
\hline
\end{tabular}

Source: HCM [11] 
2). Performance Measures (PMs) Method

Khisty [12] developed a quantitative method (Table 2) to determine the pedestrian LOS based on almost same criteria proposed by Sarker. Although Khisty's method provides a quantitative measure of pedestrian LOS on a 5 point scale, the results from this scale is not easy to interpret.

Table 2. Measurement of Performance Measures on 5 Point scale.

\begin{tabular}{lll}
\hline Service Quality & Value Range & Mark \\
\hline LOS A & greater or equal to $80 \%$ satisfied & 5 point \\
LOS B & greater or equal to $60 \%$ satisfied & 4 point \\
LOS C & greater or equal to $45 \%$ satisfied & 3 point \\
LOS D & greater or equal to 30\% satisfied & 2 point \\
LOS E & greater or equal to $15 \%$ satisfied & 1 point \\
LOS F & less than $15 \%$ satisfied & 0 point \\
\hline
\end{tabular}

Source: Khisty [12]

\section{Analysis and Discussion: Pedestrian Level of Service}

\subsection{Percentage of Respondents}

To collect the qualitative data three selected areas have surveyed, total respondents is 98 with $95 \%$ confidence level and 5 confidence interval of which 43 sample from commercial area, 40 from mixed use area and 15 sample from residential area are collected (Figure 2). Purposive sampling technique has been used to collect the data.

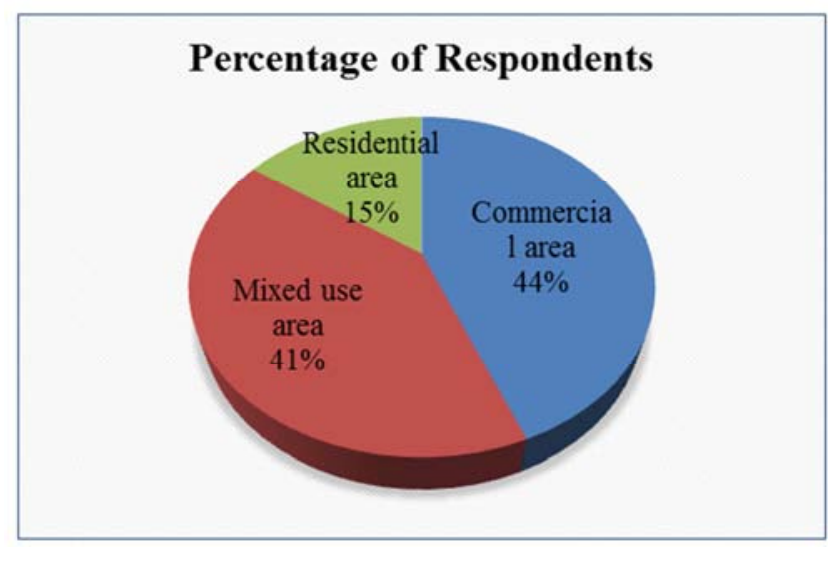

Source: Questionnaire Survey, 2017.

Figure 2. Percentage of Respondents.

\subsection{Pedestrian Count per 15 Minutes}

Pedestrians have counted at a place per $15 \mathrm{~min}$ in total 2 hours. The maximum traffic flow has found in the Laxmipur area and lowest in the residential area (Figure 3).

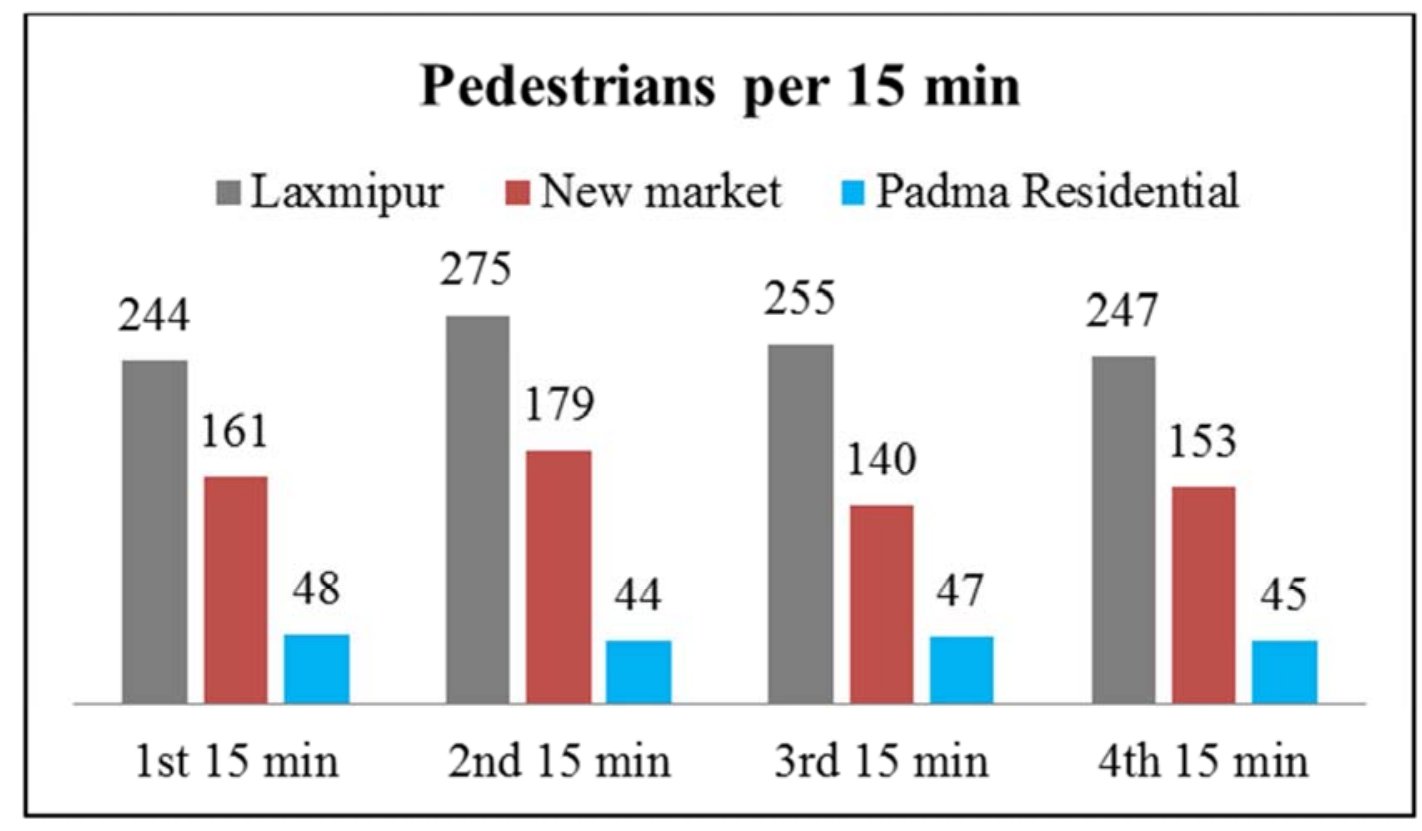

Source: Field Survey, 2017.

Figure 3. Pedestrians per 15 Minutes.

\subsection{Assessment of Pedestrian Facilities Based on Respondent's Rating}

The respondents were asked how they would rate the walkability of the area. The respondents gave weight to the parameter on the basis of 5 indicators. These are "very good", "good", "moderate", "bad" and "very bad". Almost 35.5\% were rate it as the Moderate and $1.8 \%$ were rate it as very bad (Figure 4 ). 


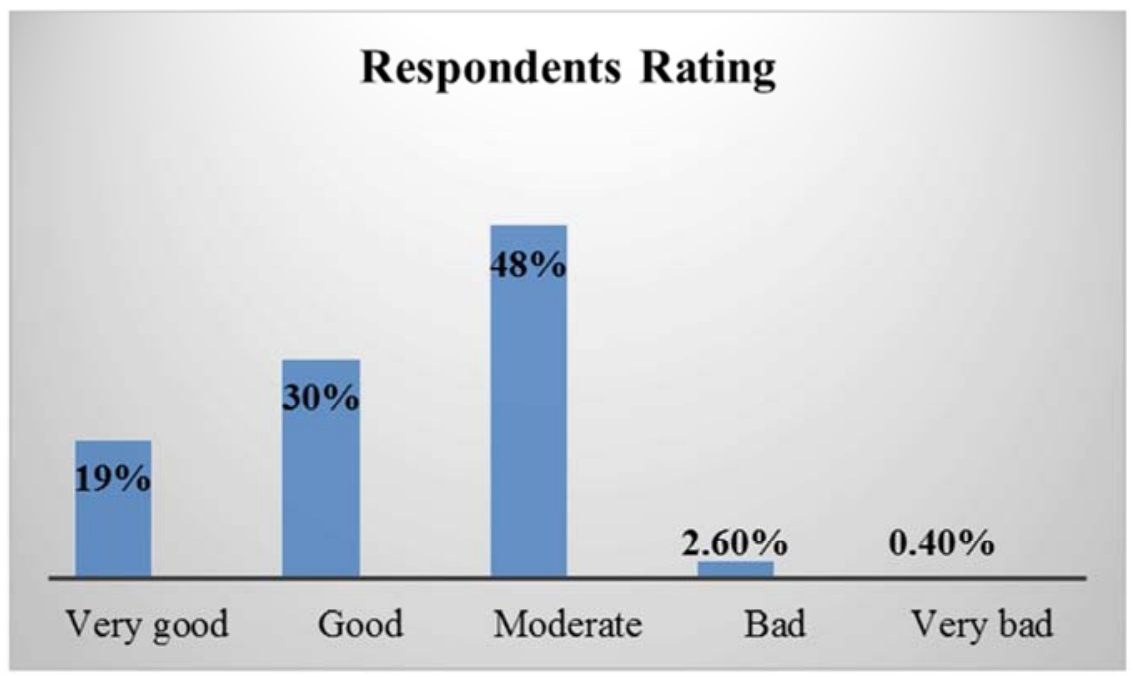

Source: Questionnaire Survey, 2017.

Figure 4. Pedestrians per 15 Minutes.

\subsection{Respondent's Rating Regarding Quantitative Parameters}

Table 3. Respondent's Rating Regarding Quantitative Parameters.

\begin{tabular}{llllllll}
\hline Location & Land use & Effective Width & Average Space (sq. m/ped) & Flow Rate (ped/m/sec) & Speed (m/sec) & V/C Ratio & Total rating (\%) \\
\hline New Market & Commercial & 4 & 21.04 & 0.0483 & 0.969 & 0.791 & 29.80 \\
Laxmipur & Mixed & 8 & 37.34 & 0.0254 & 0.948 & 0.425 & 33.45 \\
Padma & Residential & 0 & 0 & 0 & 1.077 & 0 & 5.45 \\
Residential & & 0 & 0 & 0 & \\
\hline
\end{tabular}

Source: Questionnaire Survey, 2017.

The table 3 shows that the Laxmipur area occupies the highest score (33.45) and the Padma Residential area occupies the lowest score (5.45) in case of quantitative parameter analysis.

\subsection{Respondent's Rating Regarding Qualitative Parameters}

Table 4. Respondent's Rating Regarding Qualitative Parameters.

\begin{tabular}{llll}
\hline \multirow{2}{*}{ Parameter } & \multicolumn{3}{l}{ Rating (\%) According to Study Area } \\
\cline { 2 - 4 } & New Market & Laxmipur & Padma Residential \\
\hline Attractiveness & 5.76 & 5.75 & 5.94 \\
Comfort & 5.63 & 5.66 & 5.21 \\
Convenience & 4.50 & 3.81 & 3.88 \\
Safety & 5.31 & 5.45 & 4.36 \\
Security & 7.34 & 7.09 & 7.62 \\
System coherence & 4.18 & 3.64 & 6.42 \\
System continuity & 8.01 & 8.60 & 2.31 \\
Total Rating & 40.73 & 39.99 & 35.73 \\
\hline
\end{tabular}

Source: Questionnaire Survey, 2017.

The table 4 shows that the new market area occupies the highest score (40.73) and the Padma Residential area occupies the lowest score (35.73) in case of qualitative parameter analysis.

\subsection{Comparative Rating (\%) of the Study Area}

To perform the study two complex variables are selected, these are 'Qualitative' and 'Quantitative'. From the collected information it is found that the facilities for pedestrian are similar for new market and Laxmipur area. But quantitative rating for Laxmipur area is better than others. But very worst condition is noticed at new market area (Figure 5).

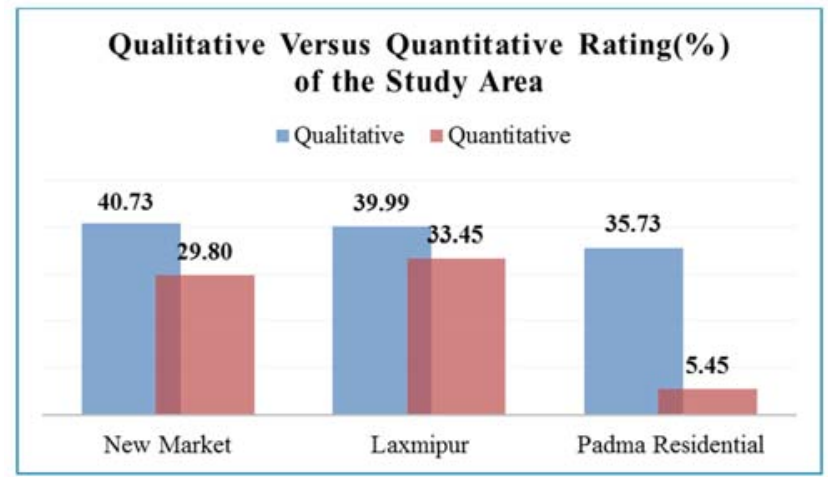

Source: Questionnaire Survey, 2017.

Figure 5. Qualitative Versus Quantitative Rating of the Study Areas.

\subsection{Total Rating (\%) of the Study Area}

Considering total rating for these three selected areas it is found that the overall rating for Laxmipur area is higher than others area (Figure 6). 


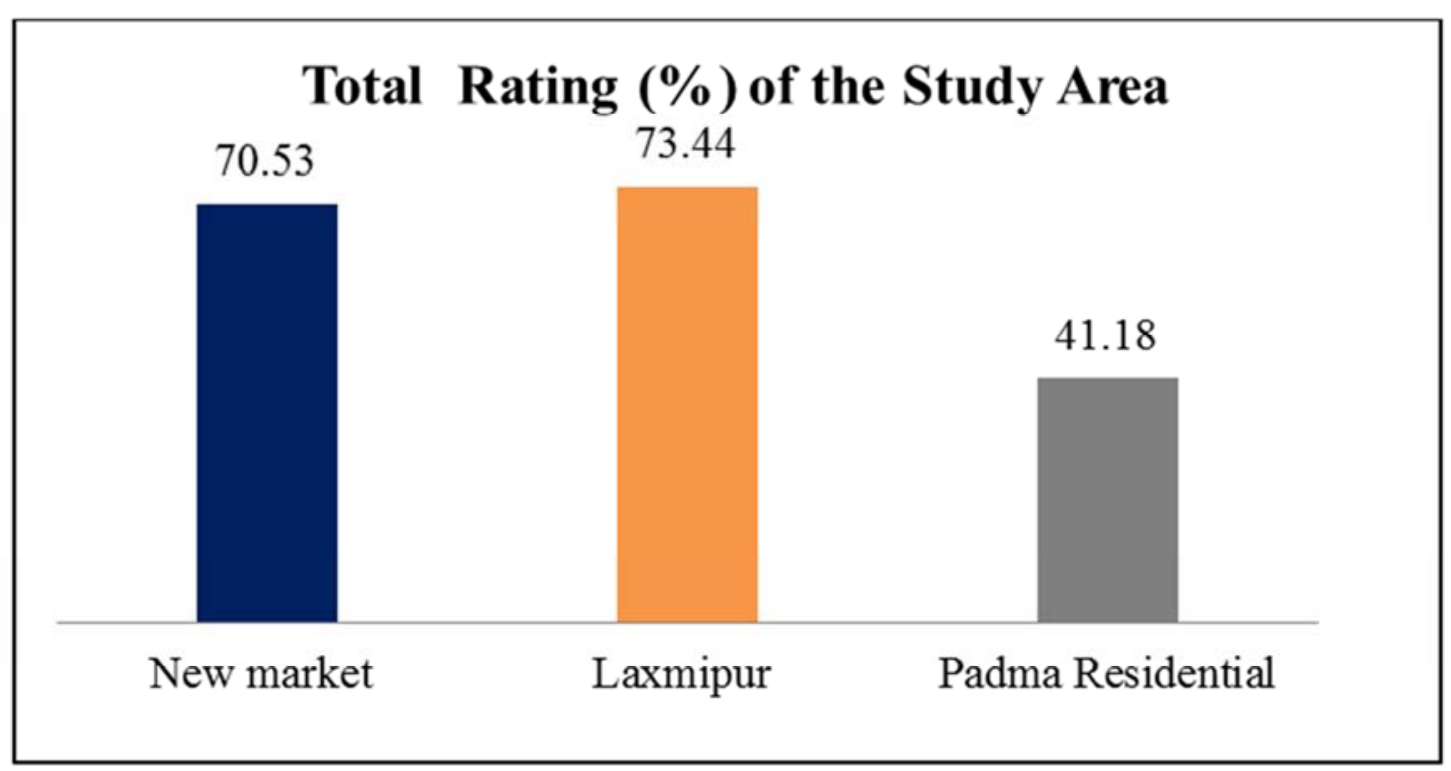

Source: Questionnaire Survey, 2017.

Figure 6. Total Rating of the Study Area.

\subsection{Level of Service of the Study Area}

Table 5. Level of service of the study area.

\begin{tabular}{lll}
\hline Area & Rating (\%) & LOS \\
\hline New market & 70.53 & $\mathrm{~B}$ \\
Laxmipur & 73.44 & $\mathrm{~B}$ \\
Padma Residential & 41.18 & $\mathrm{D}$ \\
\hline
\end{tabular}

Source: Questionnaire Survey, 2017.

From the above discussion, the following rating for three different selected areas has been found (Table 5). By applying the satisfaction level method we have found that the level of service for New market area is " $\mathrm{B}$ ", for Laxmipur area is " $\mathrm{B}$ " and for Padma Residential area is " $\mathrm{D}$ ".

\section{Analysis and Discussion: Pedestrian Behavior}

\subsection{Average Walking Speed of the Pedestrian}

Pedestrian walking speed varies according to age, gender, time of the day, category of the pedestrian(single male, single female, double male, double female, female and male with good interaction, female with kid etc.) and the interaction develops among them or not.

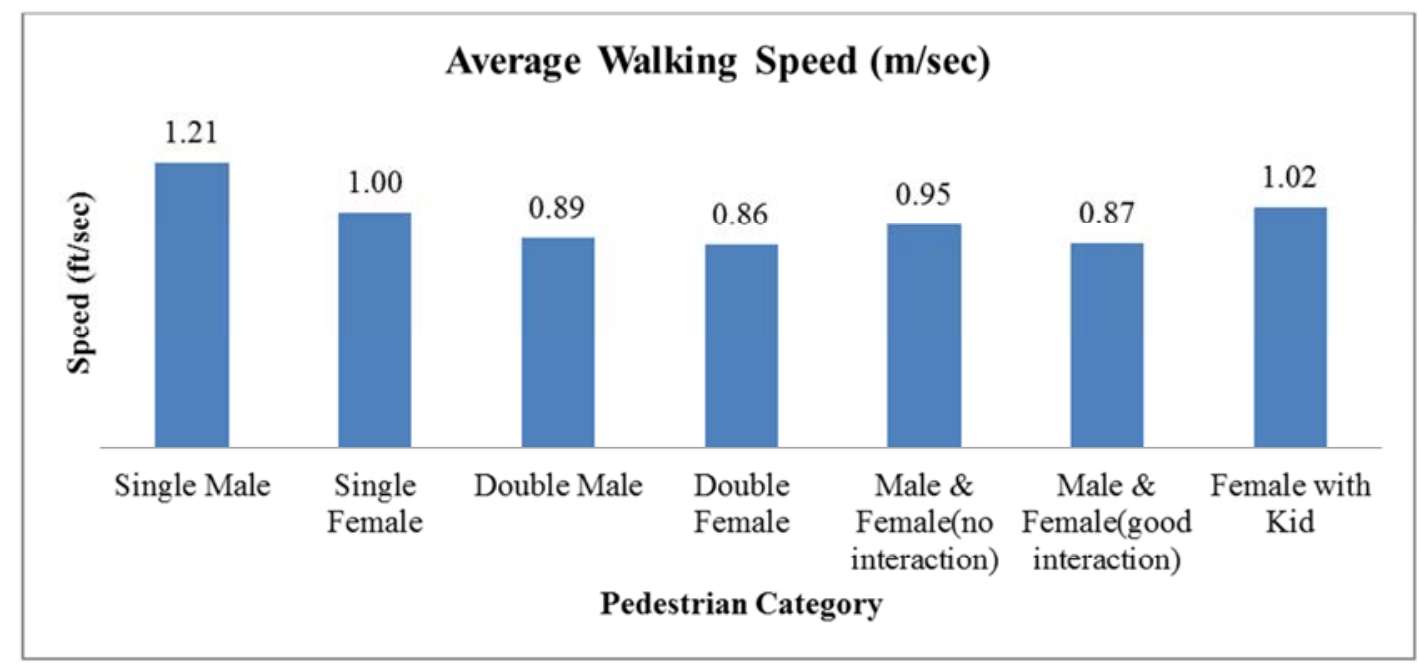

Source: Observation Survey, 2017.

Figure 7. Average Pedestrian Walking Speed (ft/sec).

The figure 7 shows that the average walking speed in case of single male is the highest in all the concerned areas, in case of double male is the lowest and in case of female with kid is the second lowest. 


\subsection{Average Walking Time of the Pedestrian}

\section{Average Walking Time}

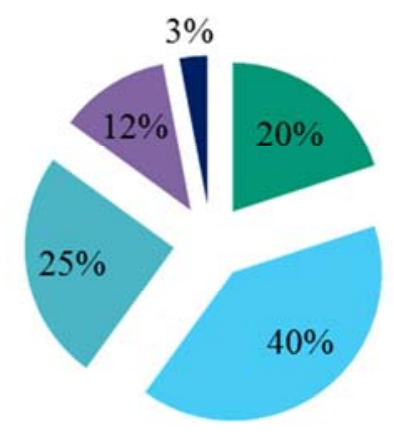

$$
\begin{aligned}
& =<10 \mathrm{~min} \\
& =10-15 \mathrm{~min} \\
& =15-20 \mathrm{~min} \\
& -20-25 \mathrm{~min} \\
& \square>25 \mathrm{~min}
\end{aligned}
$$

Source: Observation Survey, 2017.

Figure 8. Average Pedestrian Walking Time (min).

From the figure 8 , it is cleared that the preference level of the pedestrian about the average walking time changes according to duration of time. Most of the respondents (about 40\%) would like to walk for a period of about $10-15$ minutes. About $20 \%$ people would like to walk for a period less than 10 minutes. About $3 \%$ people would like to walk more than 25 minutes.

\subsection{Pedestrians' Preference for Crossing}

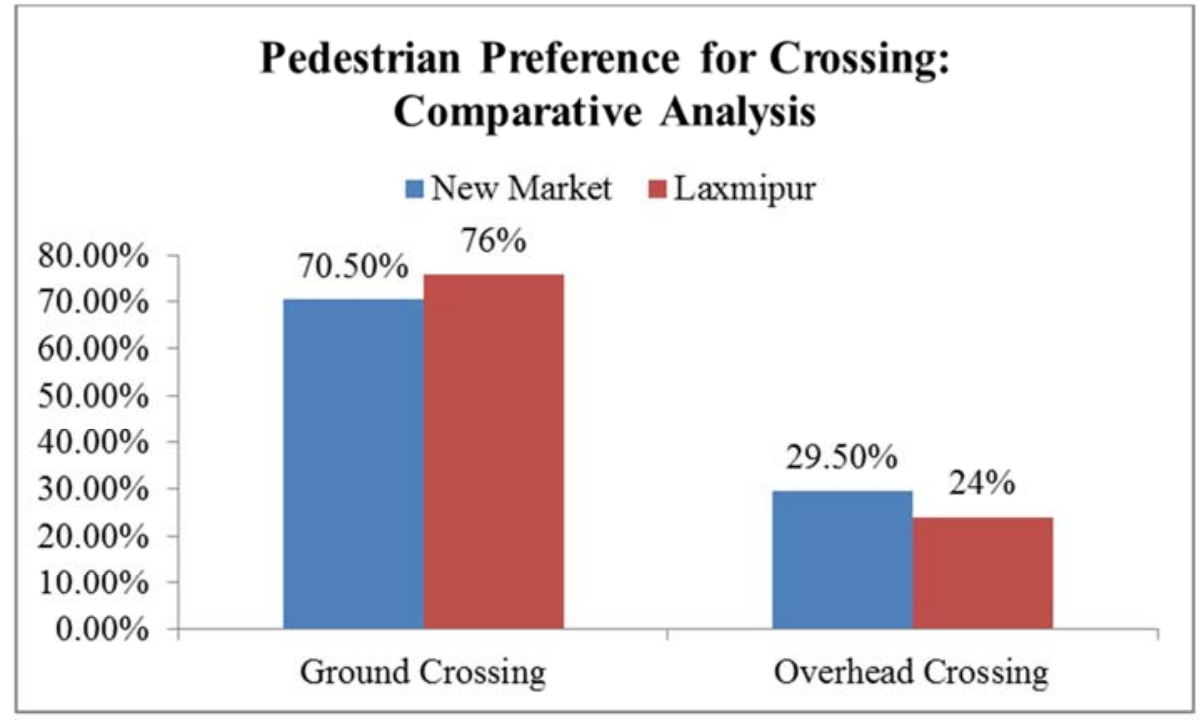

Source: Observation Survey, 2017

Figure 9. Pedestrian Preference for Crossing.

The figure 9 describes that majority of the pedestrians are willing to use ground crossing than overhead crossing while crossing the roads in both of the study areas.

\subsection{Relationship among Effective Width, Average Space and Flow Rate}

The figure 10 shows the relationship among effective width, average space and flow rate of the pedestrians. As the effective width of the footpath increases, average space for the pedestrian also increases. Again average space and flow rate are inversely related. As the average space of the pedestrians increases, flow rate of the pedestrian decreases from new market to Laxmipur area. 


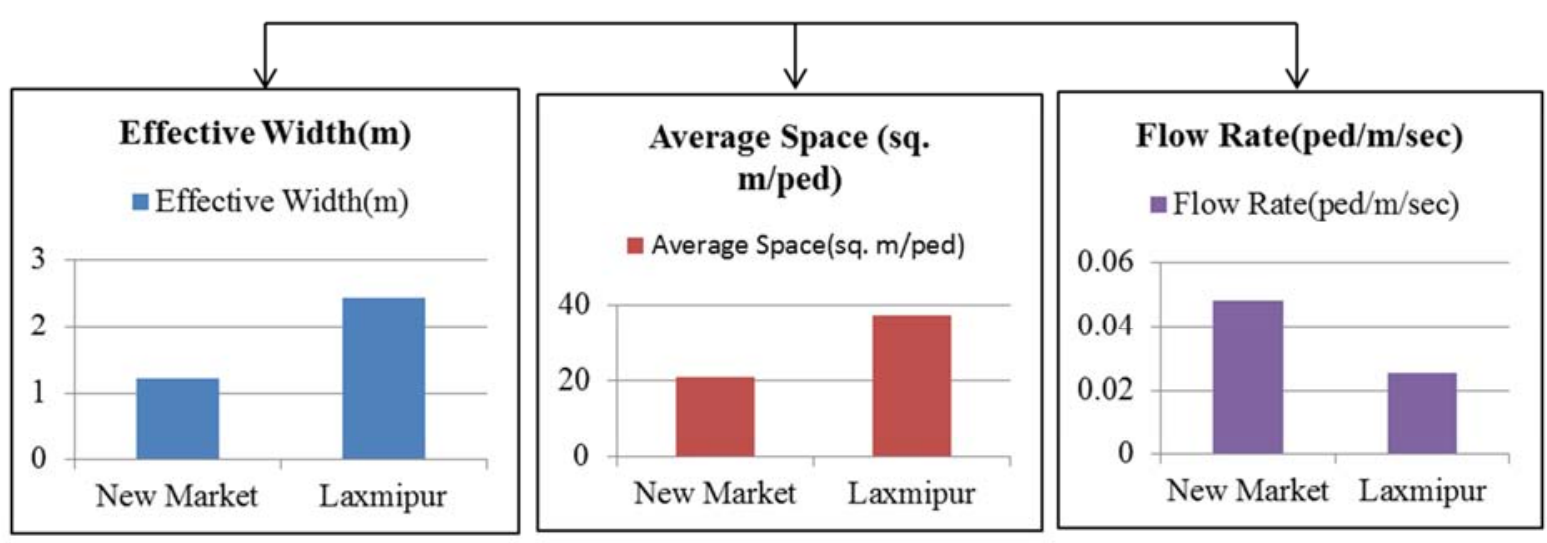

Source: Observation Survey, 2017.

Figure 10. Relationship among Effective Width, Average Space and Flow Rate.

\subsection{Relationship Between Average Space and Walking Speed}

The figure 11 shows positive relationship between average space and pedestrian speed. As the average space for the pedestrian increases, walking speed of the pedestrians also increases. The average space increases from 21.04 to $37.34 \mathrm{sq}$. $\mathrm{m} /$ ped. As a result the speed also increases from 0.969 to 0.984 $\mathrm{m} / \mathrm{sec}$ from New Market to Laxmipur area. Again there exists no defined footpath facility in the Padma Residential area. Pedestrians use the road side as the footpath. There exist less obstructions and motorized vehicles in this area. As a result the walking speed of the pedestrians in this area is higher than the commercial area and more or less the same as the mixed land use area.
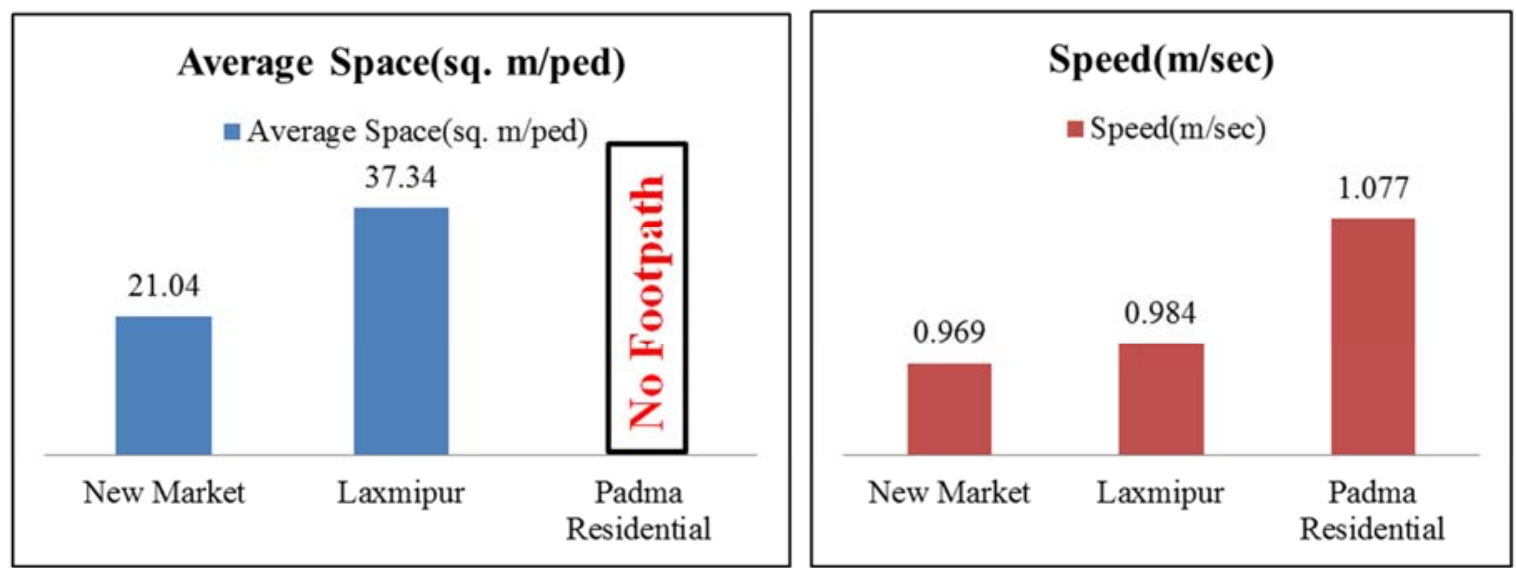

Source: Observation Survey, 2017

Figure 11. Relationship among Average Space and Speed.

\section{Major Findings and Recommendation}

\subsection{Major Findings}

1) The level of service of both the New Market(commercial area) and Laxmipur (mixed use area) is "B", which indicates Stable flow, reasonable freedom of speed and movement and the pedestrian is greater than or equal to $60 \%$ satisfied.

2) Since there exist no footpath in the Padma Residential area, the footpath infrastructure is also inadequate in this area and the level of service of the Padma Residential area is " $D$ ", which indicates Speed and ability to pass slower pedestrian restricted and the pedestrian is greater than or equal to $30 \%$ satisfied.

3) The behavior of the pedestrians changes on the basis of age, gender, obstructions on the footpath mainly illegal establishments, presence of street infrastructures and land use of the concerned area (commercial, mixed use, residential etc.).

4) Psychological environment such as: weather phenomena, temperature, wind also affects pedestrian behavior greatly.

\subsection{Pedestrians' Priority for the Development of Walking Environment}

The figure 12 shows that in New Market and Laxmipur area most of the people have given priority to rehabilitation of illegal establishment then restriction on footpath parking. As in the residential area there is no footpath so they have given their priorities to construct footpath. But many of them said that they have no problem without footpath. 


\section{Percentage Given by the Pedestrians for the Development of Walking Environment}

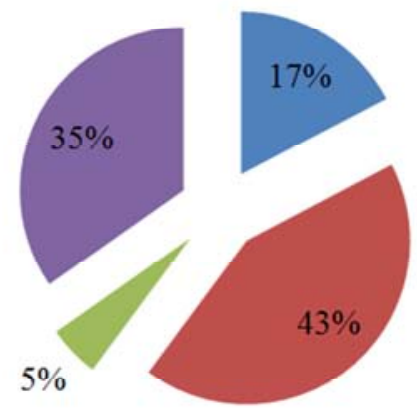

- Provision of Street Infrastructure

- Rehabilitation of Illegal Establishment

Footpath Expansion

- Restriction on Footpath Parking

Source: Questionnaire Survey, 2017.

Figure 12. Percentage Given by the Pedestrians for the Development of Walking Environment.

On the basis of pedestrians' given priority, we may conclude the following recommendations:

1) Holders of illegal establishments should be rehabilitated in a systematic way;

2) Operation of the vehicles on the footpath should be strictly restricted;

3) Street infrastructure (seating arrangement, shading, smoothness, road marking, barricades, plantation, pedestrian crossing, mapping, public telephone, traffic signs etc.) should be provided in all the areas according to pedestrians' demand to ensure better walking environment;

4) It is recommended to expand the width of the footpath in the new market area to ensure comfortable walking;

5) Disability Infrastructures (slope, stair) should be provided in all the areas;

6) Footpath infrastructures should be provided in the residential area to ensure safe and secure walking and a defined pathway for pedestrians.

\section{Conclusion}

This paper aims to investigate the pedestrian behavior and service quality of Rajshahi metropolitan city. Significant variations of pedestrians mean walking speed with respect to age and gender were found. This study also shows that the characteristics of the location have effect on the pedestrian flow characteristics. The relationships developed between different flows parameters such as: speed, flow, density are observed to be satisfactory for walkways. The results of this paper will constitute an important contribution to an active field of research and a resource for those developing pedestrian models in practice. It is expected that the results will be highly useful in the planning and design of pedestrian networks in Rajshahi and can be applied to other cities with similar pedestrian characteristics.

\section{References}

[1] Rasooli \& Sara. (2007). Sidewalk as a good urban space. Monthly paper of Road and buildings, number 63, 69.

[2] BBS, (2011). Community Report-Rajshahi, Bangladesh Bureau of Statistics, Government of the People's Republic of Bangladesh.

[3] Older, S. (1968). Movement of pedestrians on footways in shopping streets. Traffic Engineering and Control, 10, 160-163.

[4] Tanaboriboon, Y., \& Guyano, J. (1991). Analysis of pedestrian movements in Bangkok. Transportation Research Record, (1294), 52-56.

[5] Bernhoft, I. M., \& Carstensen, G. (2008). Preferences and behavior of pedestrians and cyclists by age and gender'. Transportation Research Part F, 11, 83-95.

[6] Rosenbloom, T., Nemrodov, D., Barkan, H. (2004). Pedestrians' behavior in an ultraorthodox and a non-orthodox city. Transportation Research Part F, 7, 395-404.

[7] Holland, C., \& Hill, R. (2007). The effect of age, gender and driver status on pedestrians' intentions to cross the road in risky situations, Accident Analysis and Prevention, 39, 224-237.

[8] Hamed, M. M. (2001). Analysis of pedestrians' behavior at pedestrian crossings. Bangladesh Institute of Planners, Safety Science, 38, 63-82.

[9] Rahman, D. K., Afrin, S., \& Alum, A. (2006). How safe are the walkways in Dhaka city? An empirical study, Road Safety in Developing Countries, Accident Research Center, BUET, Dhaka, 78-83.

[10] Landis, B. W. (2001). Modeling the roadside walking environment: Pedestrian level of service. Transportation Research Record, (1773), 82-88.

[11] HCM (2010). Highway Capacity Manual. Washington, D. C.: Transportation Research Board. 
[12] Khisty, C. J. (1994). Evaluation of Pedestrian Facilities: Beyond the Level-of-Service Concept. Transportation Research Record, 1438, 46-49.

\section{Biography}

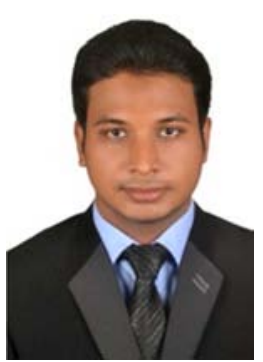

\section{Md. Shakil Ar Salan}

Md. Shakil Ar Salan was born in Chapai Nawabganj, Bangladesh in 1994. He received his Secondary and Higher Secondary School Certificate in 2010 and 2012 respectively. He is an undergraduate student at Department of Urban and Regional Planning in Rajshahi University of Engineering and Technology (RUET), Rajshahi-6204, Bangladesh. He attended on several GIS and Remote Sensing based training program, National Conference on Disaster Forecasting and Management and Consultation program on Environmental Protection. His research and publication interest include Tourism Planning and Management, Traffic and Transportation Planning, Environmental Planning and Management.

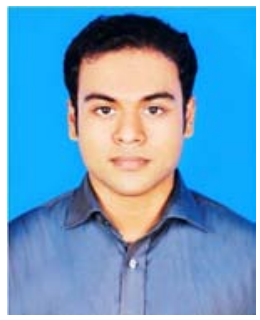

\section{Md. Nahidul Islam}

Md. Nahidul Islam was born in Tangail, Dhaka, in 1994. In 2008, he received Junior School Certificate award. He received his Secondary and Higher Secondary School Certificate in 2010 and 2012 respectively. He is an undergraduate student at Department of Urban and Regional Planning in Rajshahi University of Engineering and Technology (RUET), Rajshahi-6204, Bangladesh. He attended on several GIS and Remote Sensing based training program. His research and publication interest include Satellite image processing and analysis, Different hazard and disaster related issue analysis, Traffic simulation modeling.

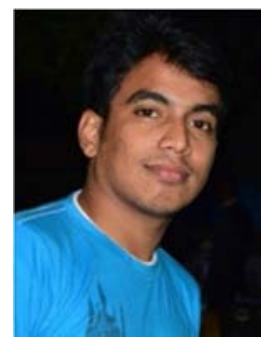

\section{Shazzu Rahman}

Md. Shazzu Rahman was born in Naogoan district, 20 october 1994. He passed his secondary and higher secondary examination in 2010 and 2012 respectively. $\mathrm{He}$ is an undergraduate student of department of urban and regional planning. He attended several GIS and remote sensing seminar and environmental related seminar. His interested field includes

GIS and remote sensing, environmental science, and economic.

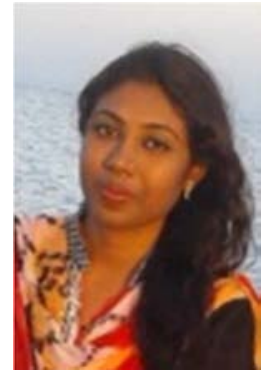

Hafiza Nazneen Labonno

Hafiza Nazneen Labonno was born in Jessore, Khulna, in 1995. In 2008, she received Junior School Certificate award. She received her Secondary and Higher Secondary School Certificate in 2010 and 2012 respectively. She is an undergraduate student at Department of Urban and Regional Planning in Rajshahi University of Engineering and Technology (RUET), Rajshahi-6204, Bangladesh. She attended on several GIS and Remote Sensing based training program. Her research and publication interest include Satellite image processing and analysis, Different hazard and disaster related issue analysis.

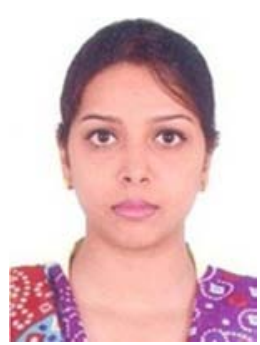

\section{Nazia Hossain}

Nazia Hossain presently teaching as a lecturer of Urban and Regional Planning, RUET, Rajshahi-6204, Bangladesh. She did her graduation in Urban and Regional Planning (URP) from Bangladesh University of Engineering and Technology (BUET), Dhaka in 2014. She is also continuing Masters of Urban and Regional Planning (MURP) in the same department from the same university. Her research and publication interest include Disaster Management and Urban Planning.

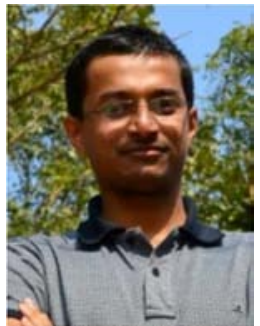

Hossain Mohiuddin

Hossain Mohiuddin presently teaching as a lecturer of Urban and Regional Planning, RUET, Rajshahi-6204, Bangladesh. He did his graduation in Urban and Regional Planning (URP) from Bangladesh University of Engineering and Technology (BUET), Dhaka in 2014. He is also continuing Masters of Urban and Regional Planning (MURP) in the same department from the Lowa university, US. His research and publication interest include Regional Planning, Transportation Planning. 